\title{
Let-7a-5p regulates the inflammatory response in chronic rhinosinusitis with nasal polyps
}

\author{
Jianwei Zhang ${ }^{1 \dagger}$, Lei $\mathrm{Han}^{2 \dagger}$ and Feng $\mathrm{Chen}^{3 *}$
}

\begin{abstract}
Background: Let-7a-5p is demonstrated to be a tumor inhibitor in nasopharyngeal carcinoma. However, the role of let-7a-5p in chronic rhinosinusitis with nasal polyps (CRSwNP) has not been reported. This study is designed to determine the pattern of expression and role of let-7a-5p in CRSwNP.

Methods: The expression level of let-7a-5p, TNF-a, IL-1 3 , and IL-6 in CRSwNP tissues and cells were detected by RTqPCR. Western blot assay was carried out to measure the protein expression of the Ras-MAPK pathway. Dual luciferase reporter assay and RNA pull-down assay were used to explore the relationship between let-7a-5p and IL-6.

Results: Let-7a-5p was significantly downregulated in CRSwNP tissues and cells. Moreover, the mRNA expression of TNF- $a$, IL-1 $\beta$ and IL- 6 was increased in CRSwNP tissues, while let-7a-5p mimic inhibited the expression of TNF- $a$, IL-1 $\beta$ and IL-6. Besides that, let-7a-5p was negatively correlated with TNF-a, IL-1 $\beta$ and IL-6 in CRSwNP tissues. In our study, IL6 was found to be a target gene of let-7a-5p. Additionally, let-7-5p mimic obviously reduced the protein levels of Ras, p-Raf1, p-MEK1 and p-ERK1/2, while IL-6 overexpression destroyed the inhibitory effect of let-7a-5p on the Ras-MAPK pathway in CRSwNP.
\end{abstract}

Conclusion: We demonstrated that let-7a-5p/IL-6 interaction regulated the inflammatory response through the RasMAPK pathway in CRSWNP.

Keywords: Chronic rhinosinusitis with nasal polyps, Inflammatory response, IL-6, Let-7a-5p, Ras-MAPK

\section{Introduction}

Chronic rhinosinusitis (CRS) is one of the common chronic diseases in otorhinolaryngology, and its incidence rate is increasing year by year [1]. At present, CRS is divided into two types: CRS with nasal polyps (CRSwNP) and CRS without nasal polyps (CRSsNP) [2]. CRSwNP is characterized by eosinophilic inflammation of the nasal-sinus mucosa [3]. The main symptoms include

\footnotetext{
* Correspondence: wunyovggs403776@163.com

${ }^{\dagger} J$ ianwei Zhang and Lei Han contributed equally to this work.

${ }^{3}$ Department of Otorhinolaryngology-Head and Neck Surgery/ Research Institution of Otorhinolaryngology, Nanjing Drum Tower Hospital (The Affiliated Hospital of Nanjing University Medical School), Nanjing 210008, Jiangsu Province, China

Full list of author information is available at the end of the article
}

nasal congestion, sticky or purulent nasal discharge, headache, and hyposmia or loss of sense of smell [4]. The chronic recurrent CRSwNP seriously affects the patient's quality of life and brings a heavy economic burden. Some cases of refractory CRSwNP cannot be reversed by surgery or antimicrobial therapy, which is also a very challenging situation for both patients and doctors [5]. It is currently believed that the inflammatory response of Th2 cells caused by microbial stimulation is the main cause of CRSwNP [6]. However, no specific pathogens or exogenous stimuli were directly associated with the development of CRSwNP. Although many studies have been conducted on the role of chronic inflammation

(c) The Author(s). 2021 Open Access This article is licensed under a Creative Commons Attribution 4.0 International License, which permits use, sharing, adaptation, distribution and reproduction in any medium or format, as long as you give appropriate credit to the original author(s) and the source, provide a link to the Creative Commons licence, and indicate if changes were made. The images or other third party material in this article are included in the article's Creative Commons licence, unless indicated otherwise in a credit line to the material. If material is not included in the article's Creative Commons licence and your intended use is not permitted by statutory regulation or exceeds the permitted use, you will need to obtain permission directly from the copyright holder. To view a copy of this licence, visit http://creativecommons.org/licenses/by/4.0/ The Creative Commons Public Domain Dedication waiver (http://creativecommons.org/publicdomain/zero/1.0/) applies to the data made available in this article, unless otherwise stated in a credit line to the data. 
in the development of CRSwNP, the underlying mechanism remains unclear.

MicroRNA (miRNA) is a type of endogenous noncoding single-stranded small RNA with a length of about 22 nt [7]. It can regulate the expression of target genes after transcription by cutting the transcription products or inhibiting the translation of the transcription products $[8,9]$. MiRNAs are widely involved in various of biological events and the pathogenesis of a variety of diseases [10]. It was found that miR-125b was involved in the pathogenesis of acidophilic CRSwNP by suppressing 4E-BP1expression [11]. Moreover, Liu et al. discovered that miR-124 participated in the regulation of inflammatory response by mediating the expression of AHR in CRSwNP [12]. Previous studies have demonstrated that let-7a-5p is down expressed in various human tumors [13]. For example, let-7a-5p was found to suppress cell proliferation, migration and invasion in triple-negative breast cancer [14]. Moreover, let-7a-5p inhibited cell growth, metastasis and the doxorubicin resistance in prostate cancer [15]. However, the role of let-7a-5p in CRSwNP has not been elaborated.

In this study, we detected the expression pattern of let-7a-5p in CRSwNP, and explored its effect on inflammatory factors. Besides that, we demonstrated that let-7a$5 \mathrm{p}$ regulated the inflammatory response by modulating IL-6 expression in CRSwNP.

\section{Materials and methods \\ Clinical samples}

Twenty CRSwNP tissues and normal nasal mucosa tissues were collected from patients with CRSwNP from 2018 to 2019 at Shanghai Pudong New District Gongli Hospital/ Second Military Medical University Affiliated Hospital. Among the 20 tissues, 14 cases are edema type, 4 cases are glandular hyperplasia type, and 2 cases are fibrous type. CRSwNP tissues were collected from nasal polyps in the middle nasal meatus of patients, and normal nasal mucosa tissues were collected from the inferior turbinate of patients. All patients had no history of allergies, asthma, or aspirin sensitivity within 8 weeks before the biopsy, and did not receive topical or systemic steroids, non-steroidal anti-inflammatory drugs, antihistamines or antibiotics. The general information of 20 patients with CRSwNP is shown in Table 1. This study was approved by the Medical Ethics Committee of Shanghai Pudong New District Gongli Hospital/ Second Military Medical University Affiliated Hospital. Each patient signed the informed consent.

\section{Cell culture}

NorDFs cells were isolated from surgical tissues, and NPDFs cells were obtained from patients undergoing CRSwNP endoscopic sinus surgery. Cells were cultured
Table 1 Clinical characteristics of CRSwNP patients

\begin{tabular}{ll}
\hline & CRSwNP \\
\hline Sample number & 20 \\
Mean age (years) & $50 \pm 3.5$ \\
Male \% & $12(60 \%)$ \\
Female\% & $8(40 \%)$ \\
Allergy (\%) & $10(50 \%)$ \\
Asthma (\%) & $5(25 \%)$ \\
CT score & $19(14-21)$ \\
Endoscopic score & $2(2-3)$ \\
Asthma comorbidity & 0 \\
Aspirin intolerance & 0 \\
\hline
\end{tabular}

CRSWNP Chronic rhinosinusitis with nasal polyps

with Dulbecco's Modified Eagle Medium (DMEM) with 10\% Foetal Bovine Serum (FBS), 10,000 mg/ml penicillin and $10,000 \mathrm{mg} / \mathrm{ml}$ streptomycin. Cells were trypsinized with $0.05 \%$ Ethylene Diamine Tetraacetic Acid (EDTA). The purity of NorDFs and NPDFs cells was confirmed microscopically by their characteristic spindle cell morphology.

\section{Cell transfection}

Cells were cultured in 6-well plates. After $24 \mathrm{~h}$ of incubation, the cells were randomly divided into control group, miR-NC group, let-7a-5p mimic group, let-7a-5p mimic + pcDNA3.1-IL-6 group. Let-7a-5p mimic and miR-NC were purchased from GenePharma (Shanghai, China). The full-length sequences of IL- 6 were respectively synthesized and cloned into pcDNA3.1 (Invitrogen, Carlsbad, USA) plasmid to produce pcDNA3.1-IL-6. Lipofectamine 3000 (L3000015, Thermo Fisher Scientific, USA) was used as a transfection reagent for cell transfection.

\section{RNA extraction and reverse transcription-quantitative (RT-q) PCR assay}

Total RNA was extracted by TRIZOL reagent (Invitrogen, Thermo Fisher Scientific, Inc., USA). The cDNA template was synthesized by reverse transcription in the PCR Amplifier, and RT-qPCR was conducted with ABI7500 (Applied Biosystems, USA). The reaction conditions were initial denaturation at $95^{\circ} \mathrm{C}$ for $10 \mathrm{~min}$, followed by 40 cycles of denaturation at $95^{\circ} \mathrm{C}$ for $10 \mathrm{~s}$, annealing at $60^{\circ} \mathrm{C}$ for $20 \mathrm{~s}$, and extension at $72{ }^{\circ} \mathrm{C}$ for 34 s. The $2^{-\Delta \Delta \mathrm{Ct}}$ method was used to analyze the experimental results. U6 was the endogenous control of let-7a$5 \mathrm{p}$, while GAPDH was used as the endogenous control of IL-6, TNF- $\alpha$, and IL-1 $\beta$. The primer sequences were synthesized by Shanghai Sangon Bioengineering Co., LTD. (Shanghai, China), and were shown in Table 2. 
Table 2 The primers sequences in qRT-PCR

\begin{tabular}{|c|c|c|}
\hline Gene & & Primers sequences \\
\hline let-7a-5p & Forward & 5'-GGGAGAAGTCCGCTGGTGTTG-3' \\
\hline let-7a-5p & Reverse & 5'-CTGATCTCCTTGTTCAAGTTCA-3' \\
\hline U6 & Forward & 5'-CTCGCTTCGGCAGCACA-3' \\
\hline U6 & Reverse & 5'-AACGCTTCACGAATTTGCGT-3' \\
\hline TNF-a & Forward & 5'-CACCATGAGCACTGAAAGCA-3' \\
\hline TNF-a & Reverse & 5'-GCTCTTGATGGCAGAGAGGAG-3' \\
\hline$I L-1 \beta$ & Forward & 5'-TTCGAGGCACAAGGCACAAC-3' \\
\hline$I L-1 \beta$ & Reverse & 5'-CTGGAAGGAGCACTTCATCTGT-3' \\
\hline IL-6 & Forward & 5'-ACCCCCAGGAGAAGATTCCA-3' \\
\hline IL-6 & Reverse & 5'-GTCTTCCCCCACACCAAGTT-3' \\
\hline GAPDH & Forward & 5'-GCCACAACGACCCCTTCATG-3' \\
\hline GAPDH & Reverse & 5'-TGCCAGTGAGCTTCCCGTTC-3' \\
\hline
\end{tabular}

\section{ELISA assay}

ELISA assay was used to detect the levels of inflammatory cytokines IL-6, TNF- $\alpha$ and IL-1 $\beta$. Venous blood (1 $\mathrm{ml}$ ) was centrifuged at $3000 \mathrm{rpm}$ for $10 \mathrm{~min}$. Then the supernatant was collected in EP (eppendorf) tubes and stored at $-70^{\circ} \mathrm{C}$. The levels of IL- 6 , TNF- $\alpha$, and IL- $1 \beta$ were tested by kits from R\&D (R\&D, USA) according to the manufacturer's instructions. After incubation at room temperature for $2 \mathrm{~h}$, and then incubated with horseradish peroxidase $(200 \mu \mathrm{L})$ for another $2 \mathrm{~h}$. Then, added $200 \mu \mathrm{L}$ TMB-HCL and incubated in darkness at room temperature for $30 \mathrm{~min}$. Finally, $50 \mu \mathrm{L} \mathrm{H}_{2} \mathrm{SO}_{4}(2$ $\mathrm{mol} / \mathrm{L}$ ) was added to each well plate. After $30 \mathrm{~min}$, the absorbance at $450 \mathrm{~nm}$ was determined with a microplate reader.

\section{Western blot assay}

The protein concentration was measured by using the BCA kit (ThermoFisher Scientific, USA). The protein sample was added with $5 \times$ Loading buffer, boiled in water for $10 \mathrm{~min}$, and then carried out sodium dodecyl sulfate polyacrylamide gel electrophoresis (SDS-PAGE) protein electrophoresis. After the electrophoresis, the protein was transfected to the polyvinylidene difluoride (PVDF) membrane, and blocked with 5\% skim milk for $2 \mathrm{~h}$ at room temperature. The membranes were incubated with specific antibodies (Rabbit anti-Human, anti-GAPD H, Ras, p-Raf1, Raf1, p-MEK1, MEK1, p-ERK1/2, ERK1/2, 1:1000, Abcam) overnight at $4{ }^{\circ} \mathrm{C}$. Then, membranes were incubated with the horseradish peroxidase-conjugated antibody (Goat anti-Rabbit IgG, 1:1000, Sigma) at room temperature for $1 \mathrm{~h}$. ECL reagent (Beyotime) was used to detect the protein signals.

\section{Dual luciferase reporter assay}

The combination of let-7a-5p and IL-6 in the 3'-UTR region was predicted by Targetscan software. According to the predicted results, the mutant and wild sequences of let-7a-5p and IL- 6 binding sites were designed, respectively. Mutant and wild sequence fragments were cloned and combined with the Promega vector. IL-6-Mut and IL6-Wt were transfected with let-7a-5p mimic or miR-NC, respectively. Finally, luciferase activity was detected and normalized to the Renilla luciferase activity.

\section{RNA-pull down assay}

Bio-IL-6-Wt, Bio-IL-6-Mut and Bio-NC were obtained from GenePharma (Shanghai, China). After transfection for $48 \mathrm{~h}$, the cells were lysed with RIPA buffer (Beyotime, Shanghai, China). The cell lysate was incubated with Dynabeads M-280 Streptavidin (Invitrogen, CA). Finally, the enrichment of let-7a-5p was explored by RT-qPCR.

\section{Statistical analysis}

SPSS 22.0 and GraphPad Prism 7.01 were used to analyze the data. All data were expressed as mean \pm standard deviation (SD), and all experiments were repeated three times. Unpaired Student's $t$-test was carried out to test the differences between the two groups. Moreover, multiple groups were compared using Oneway ANOVA and Tukey's test. $P<0.05$ was considered statistically significant.

\section{Results}

Let-7a-5p was down regulated in CRSwNP tissues and cells

First, we explored the expression pattern of let-7a-5p in CRSwNP by qRT-PCR assay. The results displayed that let-7a-5p was obviously downregulated in CRSwNP tissues compared with normal group ( $p<0.001$; Fig. 1a). Similarly, let-7a-5p showed a downward trend in NPDFs cells compared with NorDFs cells ( $p<0.001$; Fig. 1b).

\section{Let-7a-5p expression was negatively correlated with TNF- $a$, IL-1 $\beta$ and IL- 6}

To explore the relationship between let-7a-5p and the inflammatory factors, the expression of IL-6, TNF- $\alpha$ and IL-1 $\beta$ was detected by RT-qPCR. The results showed that TNF- $\alpha$, IL-1 $\beta$ and IL- 6 expression were obviously upregulated in CRSwNP tissues compared with the control group $(p<0.001$; Fig. $2 \mathrm{a}-\mathrm{c})$. Next, we detected the correlation between let-7a-5p and the inflammatory factors in CRSwNP tissues by Spearman's correlation analysis. We noticed that let-7a-5p expression was negatively correlated with TNF- $\alpha$ ( $p=0.0310$; Fig. $2 \mathrm{~d})$, IL-1 $\beta$ ( $p=0.0044$; Fig. $2 \mathrm{e})$, and IL-6 ( $p=0.0495$; Fig. 2f) in CRSwNP.

\section{Let-7a-5p inhibited TNF- $a$, IL-1 $\beta$ and IL- 6 expression in NPDFs cells}

To explore the specific relationship between let-7a-p and the inflammatory factors in CRSwNP, we transfected 

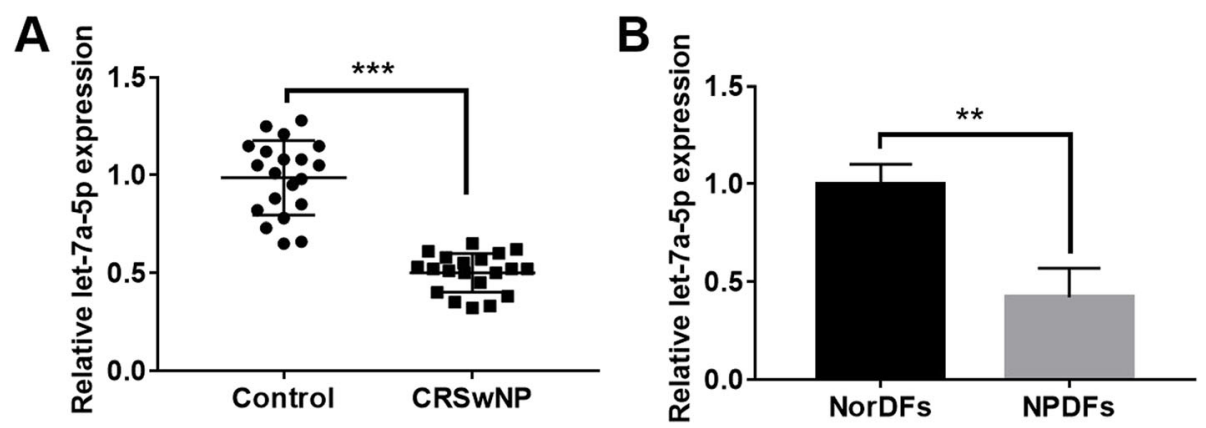

Fig. 1 let-7a-5p was down regulated in CRSwNP tissues and cells. a The expression of let-7a-5p in CRSwNP tissues and control group was detected by RT-qPCR. $\mathbf{b}$ The expression of let-7a-5p was explored in NorDFs cells and NPDFs cells. ${ }^{* * *} p<0.001$

let-7a-5p mimic into NPDFs cells. As shown in Fig. 3a, the expression of let-7a-5p was significantly increased by let-7a-5p mimic $(p<0.01)$. Then, we found that let-7a-5p mimic obviously reduced the expression of TNF- $\alpha$, IL-1 $\beta$ and IL-6 ( $p<0.01$; Fig. 3 b-d). Our findings demonstrated that let-7a-5p overexpression inhibited the inflammatory response in CRSwNP cells.

\section{Let-7a-5p inhibited the Ras-MAPK pathway in CRSwNP}

Next, we investigated the effect of let-7a-5p on the RasMAPK pathway using Western blot assay. The results displayed that let-7-5p mimic markedly reduced the protein levels of Ras, p-Raf1, p-MEK1 and p-ERK1/2, but had no effect on Raf1, MEK1 and ERK1/2 $(p<0.01$; $p<0.001$; Fig. 4). These results indicated that let-7a-5p repressed the Ras-MAPK pathway in CRSwNP.

\section{IL-6 was a downstream target gene of let-7a-5p}

As shown in Fig. 5a, there were special binding sites between let-7a-5p and IL-6. To verify this hypothesis, dual luciferase reporter and RNA pull down assay were used to explore the relationship between let-7a-5p and IL-6. We noticed that let-7a-5p mimic significantly reduced the luciferase activity of IL-6-Wt, while had little effect on IL-6-Mut ( $p<0.001$; Fig. 5b). Furthermore, an RNA pull-down assay was used to explore the association between let-7a-5p and IL6. The results displayed that endogenous let-7a-5p was also pulled down by Bio-IL-6-
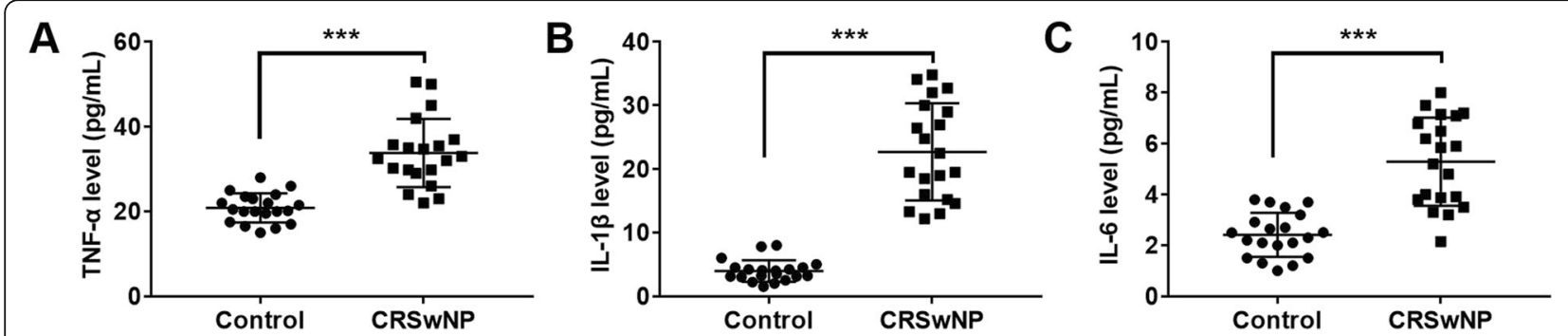

D

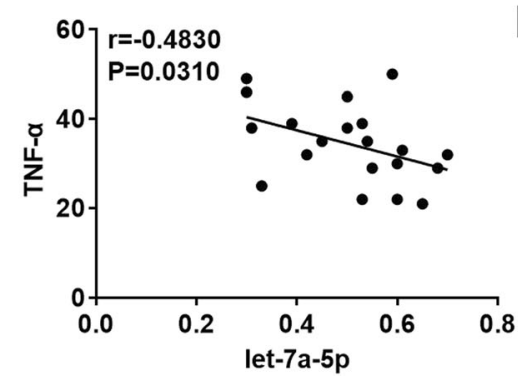

E

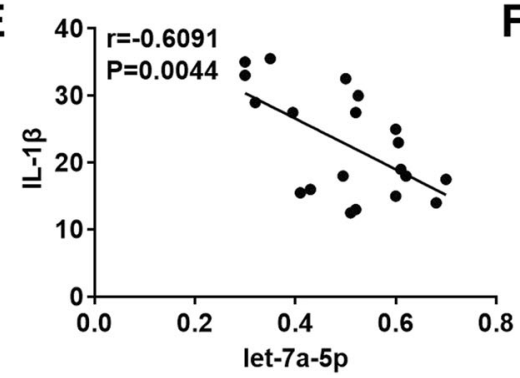

$\mathbf{F}$

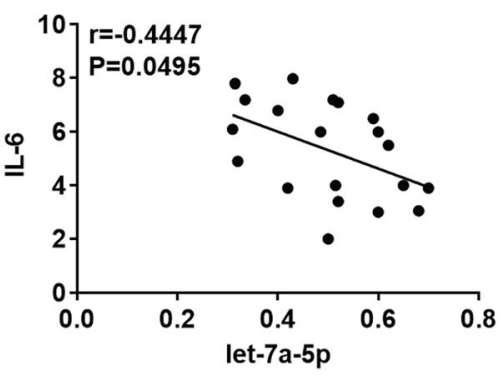

Fig. 2 Let-7a-5 $p$ was negatively correlated with the inflammatory factors. a-c The expression level of TNF- $a$, IL-1 $\beta$ and IL-6 in CRSwNP tissues was detected by ELISA assay. d-f The correlation between let-7a-5p and inflammatory factors (TNF-a, IL-1 $\beta$ and IL-6) was explored by Spearman's correlation analysis. ${ }^{* *} p<0.001$ 
A

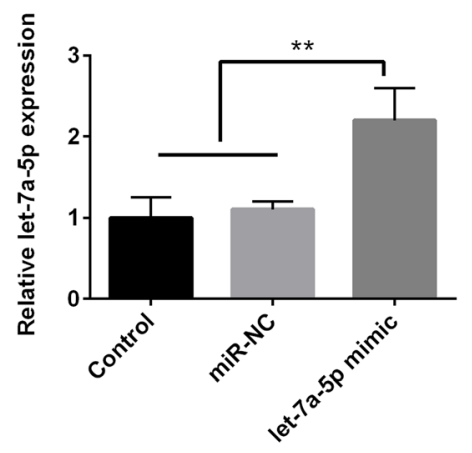

C

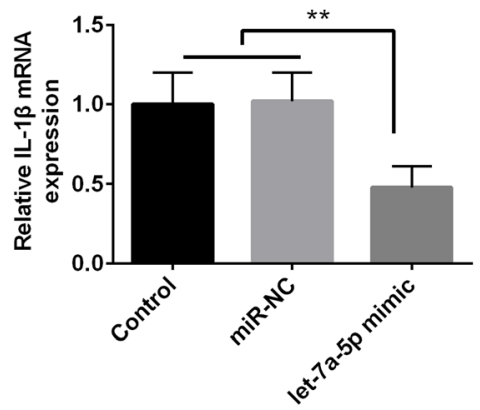

B

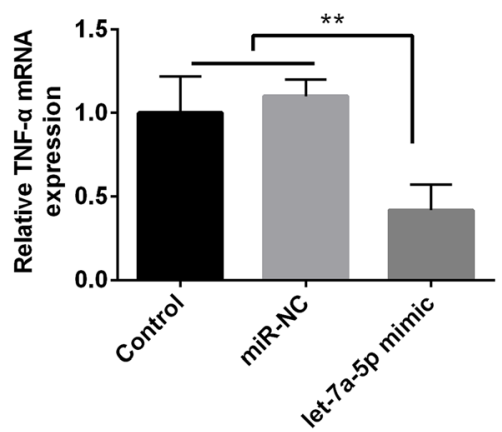

D

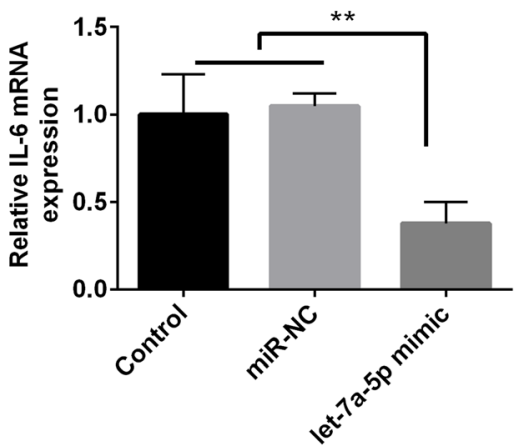

Fig. 3 Let-7a-5p inhibited TNF-a, IL-1ßand IL-6 expression in NPDFs cells. a The expression of let-7a-5p was significantly increased by let-7a-5p mimic. b-d Let-7a-5p mimic inhibited the mRNA expression of TNF- $a, I L-1 \beta$ and IL-6. ${ }^{*} p<0.01$
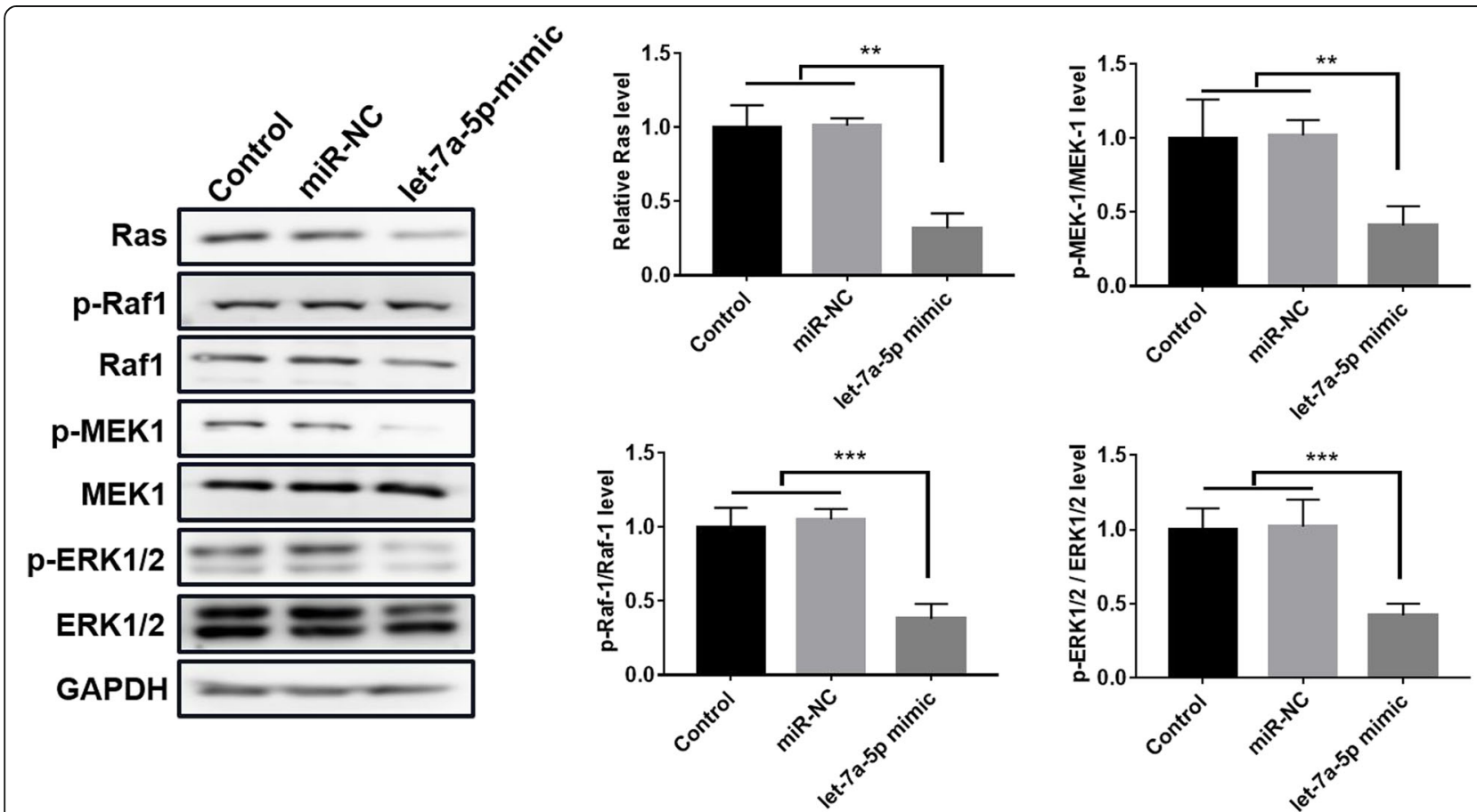

Fig. 4 let-7a-5p inhibited the activity of Ras-MAPK pathway in CRSwNP. Western bolt assay was used to explore the protein expression of Ras, Raf1, p-Raf1, MEK1, p-MEK1, ERK1/2 and $p$-ERK1/2 in NPDFs cells transfected with let-7a-5p mimic. ${ }^{* *} p<0.01 ;{ }^{* * *} p<0.001$ 
A

$$
\begin{aligned}
& \text { IL-6-Wt 5'-ucUUGGAAAGUUAGGCUUACCUCa-3' } \\
& \text { | | | | | | } \\
& \text { has-let-7a-5p 3'-ucGAUAUGUUGGAU----GAUGGAGu-5' } \\
& \text { IL-6-Mut 5'-ucUUGGAAAGUUAGgCUGACUAUu-3' }
\end{aligned}
$$

B

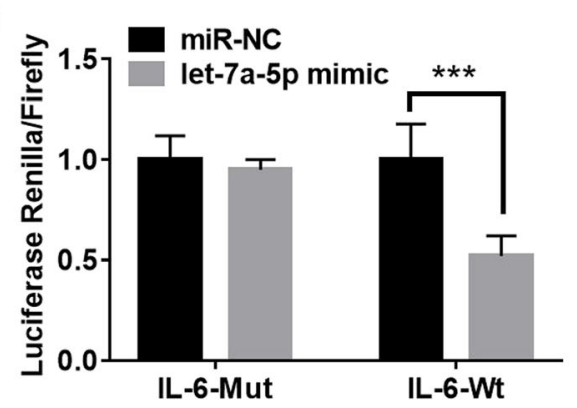

C

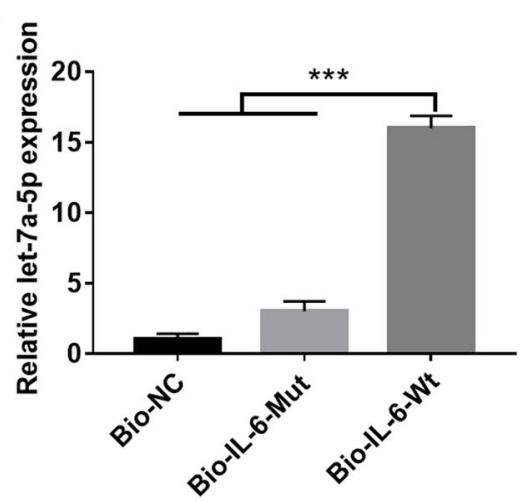

Fig. 5 IL-6 was a downstream target gene of let-7a-5p. a TargetScan predicted that there were binding sites between let-7a-5p and IL-6. b Dual luciferase reporter assay was used to detect the relationship between let-7a-5p and IL-6. c RNA pull down assay was used to investigate the binding ability of let-7a-5p and IL-6 in NPDFs cells. ${ }^{* * *} p<0.001$

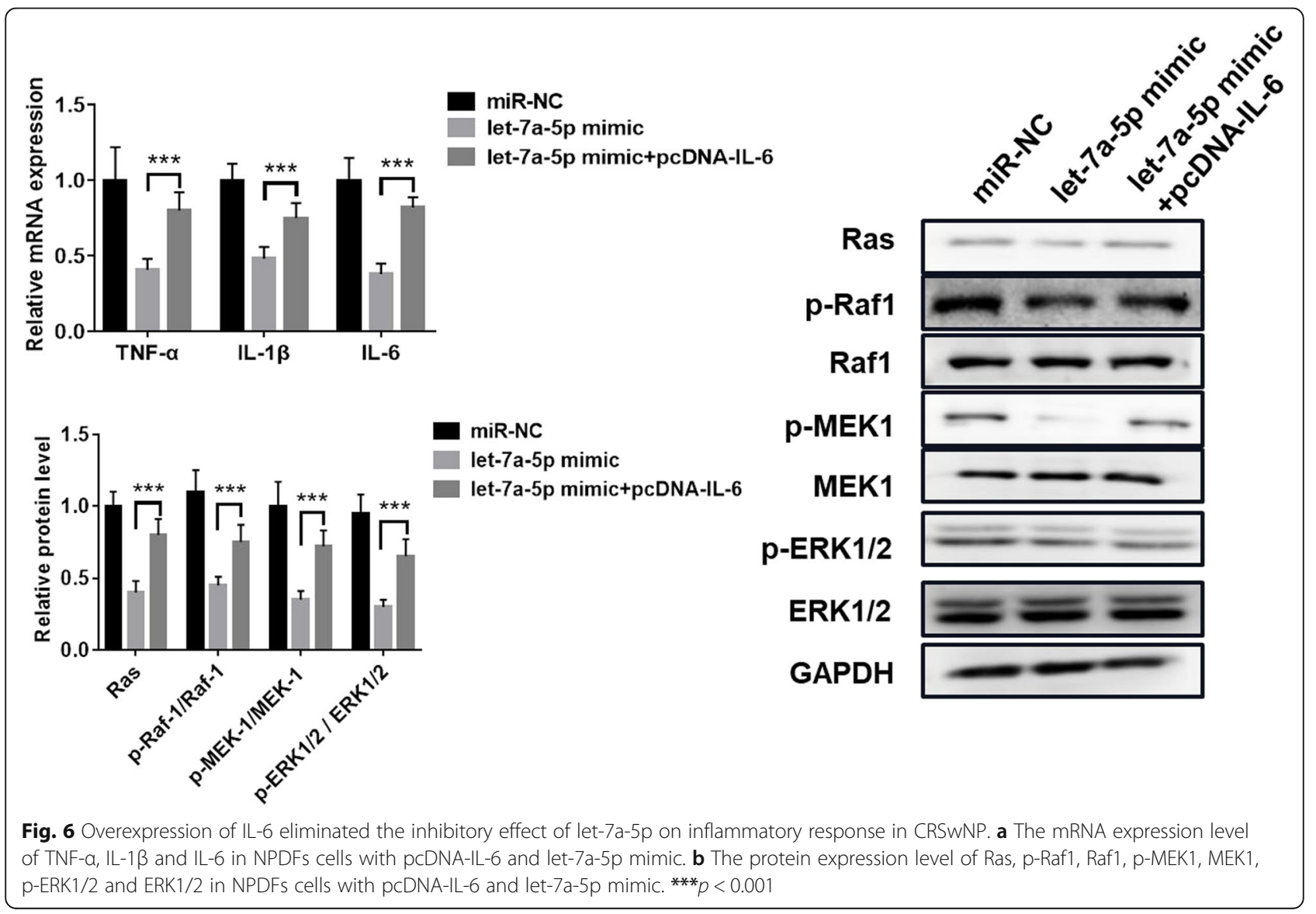


Wt, but not IL-6-Bio-Mut ( $p<0.001$; Fig. 5c). All results indicated that IL-6 was a target gene of let-7a-5p.

\section{Overexpression of IL-6 eliminated the inhibitory effect of let-7a-5p on inflammatory response in CRSwNP}

To explore the effect of let-7a-5p/IL-6 on the inflammatory response in CRSwNP, we transfected pcDNA-IL-6 into NPDFs cells with let-7a-5p mimic. We noticed that let-7a-5p mimic significantly reduced the expression of TNF- $\alpha$, IL- $1 \beta$ and IL- 6 , but IL- 6 overexpression reversed the inhibitory effect of let-7a-5p on TNF- $\alpha$, IL- $1 \beta$ and IL-6 expression ( $p<0.001$; Fig. 6a). In addition, let-7-5p mimic obviously reduced the protein levels of Ras, $p$ Raf1, p-MEK1 and p-ERK1/2, while IL- 6 overexpression destroyed the effect of let-7a-5p $(p<0.001$; Fig. 6 b). Hence, all data indicated that IL- 6 eliminated the inhibitory effect of let-7a-5p on inflammatory response in CRSwNP.

\section{Discussion}

CRSwNP is a heterogeneous disease caused by nasal inflammation and sinus mucosa inflammation. The clinical etiology and pathophysiological mechanism of nasal polyps are complex [16]. Studies performed on CRSwNP mainly focus on exploring potential inflammatory factors and targeted therapy [17, 18]. Moreover, a previous study showed that miR-4492/IL-10 interaction played a crucial role in CRSwNP [19]. Xiao et al. discovered that IL-21 was highly expressed in CRSwNP groups, and suggested that IL-21 might be a therapeutic target for CRSsNP therapy [20]. Our study demonstrated that let$7 a-5 p$ was obviously downregulated in CRSwNP tissues and cells. Intriguingly, let-7a-5p was found to be downregulated in nasopharyngeal carcinoma [21]. Next, we found that let-7a-5p inhibited the expression of TNF- $\alpha$, IL- $1 \beta$ and IL-6, and was negatively correlated with TNF- $\alpha$, IL-1 $\beta$ and IL-6.

Ras-MAPK pathway has been reported to be involved in the regulation of various multiple cellular processes, such as cell proliferation, differentiation, transcription and apoptosis, and is closely related to inflammation and oxidative stress [22]. In our study, let-7a-5p was found to suppress the Ras-MAPK pathway in CRSwNP. Similar to our findings, Liu et al. verified that NEAT1 regulated the cisplatin resistance by modulating let-7a-5p and the Ras-MAPK pathway in nasopharyngeal carcinoma [21]. On the other hand, KSR1 was found to regulate inflammatory factors' expression by activating the Ras-MAPK pathway in ischemia/reperfusion injury [23].

IL-6 is a multifunctional, multidirectional cytokine with important physiological and pathological features, and plays an important role in inflammation, immune defense and tissue damage [24]. Tian et al. found that IL-6 was upregulated in CRS, and IL-6 might be involved in the inflammation of CRS [25]. Moreover, Il6 was proved to be highly expressed in the CRS mucosa, and mediated the accumulation of inflammatory cells and participated in the inflammatory reaction process [26]. In the current work, IL-6 was proved to be a target gene of let-7a-5p. In parallel to previous studies, our data indicated that IL-6 eliminated the inhibitory effect of let-7a-5p on inflammatory response in CRSwNP.

\section{Conclusion}

In general, we found that let-7a-5p was downregulated in CRSwNP. Besides, let-7a-5p was demonstrated to regulate the inflammatory response by interacting with IL-6 through the Ras-MAPK pathway in CRSwNP. We suggested that let-7a-5p might be a possible biomarker for predicting CRSwNP. However, further experiments are needed to verify the effect of let-7a-5p on CRSwNP.

\section{Abbreviations \\ CRS: Chronic rhinosinusitis; CRSwNP: Chronic rhinosinusitis without nasal polyps; IL-6: Interleukin-6; DMEM: Dulbecco's Modified Eagle Medium; FBS: Foetal Bovine Serum; EDTA: Ethylene Diamine Tetraacetic Acid; RT- qPCR: Reverse transcription-quantitative PCR; SDS-PAGE: Sodium dodecyl sulfate polyacrylamide gel electrophoresis}

\section{Acknowledgements \\ None.}

\section{Authors' contributions}

Jianwei Zhang contributed to the collection of samples. Jianwei Zhang and Lei Han contribute to the acquisition, analysis and interpretation of data. Jianwei Zhang wrote the draft of the manuscript. Feng Chen contributed to the conception and design of this work. All authors revised the manuscript critically for important intellectual content and approved the final version to be published. Feng Chen is the guarantor of this work.

\section{Funding}

The present study was supported by the Key Disciplines Group Construction Project of Pudong Health Bureau of Shanghai (Grant No. PWZxq2017-04), Research Grant for Health Science and Technology of Pudong Health Bureau of Shanghai (Grant No. PW2019D-4), and the Key Specialty Construction Project of Health Bureau of Shanghai (Grant No. ZK2019C06).

\section{Availability of data and materials}

The datasets used or analyzed during the current study are available from the corresponding author on reasonable request.

\section{Declarations}

\section{Ethics approval and consent to participate}

This study was approved by the Medical Ethics Committee of Gongli Hospital affiliated to Naval Military Medical University/Shanghai Pudong New Area Gongli Hospital, and each patient has signed the informed consent.

Consent for publication

Written informed consent for publication was obtained from all participants.

\section{Competing interests}

The authors declare that there are no potential conflicts of interest.

\section{Author details}

'Department of Otolaryngology-Head and Neck Surgery, Shanghai Pudong New District Gongli Hospital/Second Military Medical University Affiliated Hospital, Shanghai 200135, China. ²Department of Otolaryngology-Head and Neck Surgery, Suqian First People's Hospital, The Suqian Clinical college of Xuzhou Medical University, Suqian 223800, Jiangsu Province, China. 
${ }^{3}$ Department of Otorhinolaryngology-Head and Neck Surgery/ Research Institution of Otorhinolaryngology, Nanjing Drum Tower Hospital (The Affiliated Hospital of Nanjing University Medical School), Nanjing 210008, Jiangsu Province, China.

Received: 3 November 2020 Accepted: 21 March 2021

Published online: 30 March 2021

\section{References}

1. Khan A, Vandeplas G, Huynh TMT, Joish VN, Bachert C. The Global Allergy and Asthma European Network GALEN rhinosinusitis cohort: a large European cross-sectional study of chronic rhinosinusitis patients with and without nasal polyps. Rhinology. 2018;57(1).

2. Deconde AS, Soler ZM. Chronic rhinosinusitis: epidemiology and burden of disease. Am J Rhinol Allergy. 2016;30(2):134.

3. Kim J, Kim S, Lim J, Kim D, Jeong I, Lee D, Jang Y. Association between the sinus microbiota with eosinophilic inflammation and prognosis in chronic rhinosinusitis with nasal polyps. Experimental \& molecular medicine. 2020; 52(6):978-87.

4. Chen S, Zhou A, Emmanuel B, Thomas K, Guiang H. Systematic literature review of the epidemiology and clinical burden of chronic rhinosinusitis with nasal polyposis. Curr Med Res Opin. 2020;36(11):1897-1911.

5. Weschta M, Rimek D, Formanek M, Polzehl D, Podbielski A, Riechelmann H. Topical antifungal treatment of chronic rhinosinusitis with nasal polyps: a randomized, double-blind clinical trial. J Allergy Clin Immunol. 2004;113(6): $1122-8$.

6. Batra PS, Tong L, Citardi MJ. Analysis of comorbidities and objective parameters in refractory chronic rhinosinusitis. Laryngoscope. 2013;123(S7): S1-S11.

7. O'Brien J, Hayder H, Zayed Y, Peng C. Overview of MicroRNA biogenesis, mechanisms of actions, and circulation. Front Endocrinol. 2018;9:402.

8. Pillai RS, Bhattacharyya SN, Witold F. Repression of protein synthesis by miRNAs: how many mechanisms? Trends Cell Biol. 2007;17(3):118-26.

9. Fabian $\mathrm{M}$, Sonenberg $\mathrm{N}$. The mechanics of miRNA-mediated gene silencing: a look under the hood of miRISC. Nat Struct Mol Biol. 2012;19(6):586-93.

10. Vishnoi A, Rani S. MiRNA biogenesis and regulation of diseases: an overview: springer New York; 2017

11. Zhang $X H$, Zhang YN, Li HB, Hu CY, Wang N, Cao PP, et al. Overexpression of miR-125b, a novel regulator of innate immunity, in eosinophilic chronic rhinosinusitis with nasal polyps. Am J Respir Crit Care Med. 2012;185(2):140-51.

12. Liu C, Xia M, Zhang Y, Jin P, Zhao L, Zhang J, et al. Micro124-mediated AHR expression regulates the inflammatory response of chronic rhinosinusitis (CRS) with nasal polyps. Biochem Biophys Res Commun. 2018;500(2):145-51.

13. Yao A, Xiang Y, Si YR, Fan LJ, Li JP, Li H, et al. PKM2 promotes glucose metabolism through a let-7a-5p/Stat3/hnRNP-A1 regulatory feedback loop in breast cancer cells. J Cell Biochem. 2019;120(4):6542-54.

14. Shi Y, Zhang Y, Ran F, Liu J, Lin J, Hao X, et al. Let-7a-5p inhibits triplenegative breast tumor growth and metastasis through GLUT12-mediated Warburg effect. Cancer Lett. 2020;495:53-65.

15. Bai T, Liu Y, Li B. LncRNA LOXL1-AS1/miR-let-7a-5p/EGFR-related pathway regulates the doxorubicin resistance of prostate cancer DU-145 cells. IUBMB Life. 2019;71(10):1537-51.

16. Abbas E, Li C, Xie A, Lu S, Tang L, Liu Y, et al. Distinct clinical pathology and microbiota in chronic Rhinosinusitis with nasal polyps Endotypes. The Laryngoscope. 2021;131(1):E34-44.

17. Valera FCP, Umezawa K, Brassesco MS, Castro-Gamero AM, Queiroz RGP, Scrideli CA, et al. Suppression of inflammatory cytokine secretion by an NFB inhibitor DHMEQ in nasal polyps fibroblasts. Cell Physiol Biochem. 2012; 30(1):13-22.

18. Liu CC, Sun C, Zheng X, Zhao MQ, Kong F, Xu FL, et al. Regulation of KDM2B and Brg1 on inflammatory response of nasal mucosa in CRSWNP. Inflammation. 2019;42(4):1389-400.

19. Li L, Feng J, Zhang D, Yong J, Wang Y, Yao J, et al. Differential expression of miR-4492 and IL-10 is involved in chronic rhinosinusitis with nasal polyps. Exp Ther Med. 2019;18(5):3968-76.

20. Xiao L, Wei Y, Zhang YN, Luo X, Yang BY, Yu SF, et al. Increased IL-21 expression in chronic rhinosinusitis with nasalpolyps. Clin Exp Allergy. 2015; 45(2):404-13.
21. Liu F, Tai Y, Ma J. LncRNA NEAT1/let-7a-5p axis regulates the cisplatin resistance in nasopharyngeal carcinoma by targeting Rsf-1 and modulating the Ras-MAPK pathway. Cancer Biol Ther. 2018;19(6):534-42.

22. Dhawan N, Scopton A, Dar A. Small molecule stabilization of the KSR inactive state antagonizes oncogenic Ras signalling. Nature. 2016;537(7618): 112-6.

23. Bai Y, Han G, Guo K, Yu L, Du X, Xu Y. Effect of lentiviral vector-mediated KSR1 gene silencing on the proliferation of renal tubular epithelial cells and expression of inflammatory factors in a rat model of ischemia/reperfusion injury. Acta Biochim Biophys Sin. 2018;50(8):807-16.

24. Ogura H, Murakami M, Okuyama Y, Tsuruoka M, Kitabayashi C, Kanamoto M, et al. Interleukin-17 promotes autoimmunity by triggering a positivefeedback loop via interleukin-6 induction. Immunity. 2008;29(4):628-36.

25. Tian FT, Yuan Y. Relationship and significance among IL-6,PI3K A Akt and GSK $3 \beta$ in chronic rhinosinusitis. Lin Chung Er Bi Yan Hou Tou Jing Wai Ke Za Zhi. 2016;30(23):1859-64.

26. Lee CH, Rhee CS, Min YG. Cytokine gene expression in nasal polyps. Ann Otol Rhinol Laryngol. 1998;107(8):665.

\section{Publisher's Note}

Springer Nature remains neutral with regard to jurisdictional claims in published maps and institutional affiliations.

\section{Ready to submit your research? Choose BMC and benefit from:}

- fast, convenient online submission

- thorough peer review by experienced researchers in your field

- rapid publication on acceptance

- support for research data, including large and complex data types

- gold Open Access which fosters wider collaboration and increased citations

- maximum visibility for your research: over $100 \mathrm{M}$ website views per year

At BMC, research is always in progress.

Learn more biomedcentral.com/submissions 